Rabaska

Revue d'ethnologie de l'Amérique française

\title{
Émile Maheu (1931-2008)
}

\section{Marcel Bénéteau}

Volume 6, 2008

URI : https://id.erudit.org/iderudit/019994ar

DOI : https://doi.org/10.7202/019994ar

Aller au sommaire du numéro

Éditeur(s)

Société québécoise d'ethnologie

ISSN

1703-7433 (imprimé)

1916-7350 (numérique)

Découvrir la revue

Citer ce document

Bénéteau, M. (2008). Émile Maheu (1931-2008). Rabaska, 6, 140-144.

https://doi.org/10.7202/019994ar

Ce document est protégé par la loi sur le droit d'auteur. L'utilisation des services d'Érudit (y compris la reproduction) est assujettie à sa politique d'utilisation que vous pouvez consulter en ligne.

https://apropos.erudit.org/fr/usagers/politique-dutilisation/
Cet article est diffusé et préservé par Érudit.

Érudit est un consortium interuniversitaire sans but lucratif composé de l’Université de Montréal, l'Université Laval et l'Université du Québec à Montréal. Il a pour mission la promotion et la valorisation de la recherche. https://www.erudit.org/fr/ 


\section{Émile Maheu (1931-2008)}

Le dimanche 15 juin 2008, la communauté franco-ontarienne perdait une de ses voix les mieux connues et les mieux aimées. Émile Maheu, conteur, écrivain et artiste, est décédé chez lui à Azilda, après une courte lutte contre le cancer. Il avait 77 ans. Toujours actif dans sa communauté, c'est surtout comme conteur qu'on se souviendra de « Mon oncle Émile », pour le rôle qu'il a joué dans le maintien du conte sur la place publique parmi les arts d'expression de l'Ontario français.

Ange-Émile Maheu dit Des Hazards est né dans la Beauce québécoise, à Sainte-Germaine-de-Dorchester, le 24 février 1931. Deux ans plus tard, sa famille déménage à Sainte-Aurélie, près de la frontière américaine. Quatrième de dix-sept enfants (onze sœurs et cinq frères), Émile grandit à la ferme de ses parents et travaille comme apprenti à la fromagerie de son père. Il se montre cependant très tôt doué pour les études, commençant son école primaire à l'âge

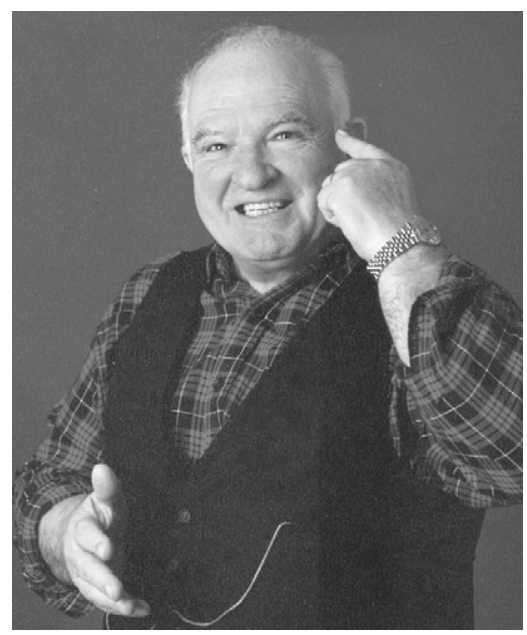

Émile Maheu

Photographie de Rachelle Bergeron, Sudbury. de cinq ans afin d'apprendre à lire luimême les bandes dessinées qu'il aime tant. Après quelques années d'études au pensionnat Saint-Louis-de-Gonzague à Québec et à l'École apostolique de Lévis, il quitte l'environnement scolaire à l'âge de 16 ans pour faire la rude vie de bûcheron, d'ouvrier et de jumper de wagons de chemin de fer. En 1950, il prend la décision de déménager en Ontario afin d'apprendre l'anglais. Il travaille comme draveur à Kapuskasing et comme bûcheron au lac Vermillion, à 50 kilomètres au nord de Sudbury. En 1951, il devient mineur et œuvre dans les mines de Stokie, Murray et Levack, ainsi qu'à la fonderie de Copper-Cliff. Il exercera le métier de hard-rock miner pendant huit ans.

En 1953, Émile épouse Marie-Claire Bonin, d'Azilda, village près de Sudbury où le couple élèvera quatre enfants. Émile avait décidé qu'il voulait une meilleure vie pour sa famille. En 1957, il complète ses études secondaires 
et entreprend son baccalauréat, ce qui mènera éventuellement à une maîtrise en éducation. Il sera alors enseignant, administrateur, conseiller pédagogique et principal surveillant avant sa retraite en 1989. Bien qu'il ait déjà produit deux petits volumes de récits, c'est à ce moment que commence véritablement une nouvelle carrière, celle de conteur. C'est effectivement une carrière pour laquelle il s'était préparé toute sa vie.

Émile Maheu a abordé le monde des contes de façon tout à fait naturelle. Son père Édouard était un conteur reconnu, en grande demande aux réunions de famille dès sa petite enfance. Il usa bien de ses talents avec sa propre famille, amusant ses enfants avec de nombreux contes qui, selon Émile, pouvaient durer des heures et des heures. Le retour des chantiers était un moment anticipé par les enfants, car ils savaient que leur père ramenait toujours avec lui de nouvelles histoires qu'il avait apprises au cours de l'hiver. La mère d'Émile était aussi conteuse, introduisant des récits un peu plus littéraires au répertoire familial ; plus tard, son grand frère Joseph a pris la relève, ajoutant lui aussi des contes des chantiers. Et comme le dit Émile : "Quand Joseph est parti de la maison, ce fut à mon tour de raconter aux plus jeunes ${ }^{1} »$.

Le jeune étudiant contait effectivement déjà à ses confrères du collège, augmentant son répertoire de sources diverses telles que Les Mille et une nuits, la Bible et la mythologie grecque, sans mentionner les bandes dessinées et les romans policiers qui ajoutaient à la sauce. Émile continua à développer ses talents : « Dans les chantiers du Maine, près de Sainte-Aurélie-de-Beauce, sur la rive est du fleuve Saint-Jean, là encore j'avais un auditoire assidu, si bien que des bûcherons s'en plaignirent au choreboy. Mes contes duraient trop longtemps et les empêchaient de se reposer pour le lendemain. Pour contrer ces plaintes, le cuisinier Dubé nous invitait à poursuivre à la cuisine. En racontant mes histoires, je me payais alors une traite dans les tartes au citron qu'il cuisinait en abondance ${ }^{2} »$. Tout passait effectivement dans le moulin à contes : « De retour au bord (du côté canadien), je racontais à mes amis les histoires apprises des autres bûcherons ou celles que j'avais lues dans les revues et journaux comme Le Samedi, Le Bulletin des agriculteurs et l'Almanach du peuple. Au magasin général, nous passions dans la cuisine de Mme Allen et, juché sur la huche à pain, je contais des contes aux amis ${ }^{3} »$.

Mais la vie d'ouvrier, les responsabilités familiales et la carrière d'enseignant ont petit à petit repoussé l'art du conteur en arrière-plan. Émile Maheu mena une vie pleine et active dans sa communauté. Nommons à titre

1. Donald Deschênes et Émile Maheu, Les Contes d'Émile et une nuit, Sudbury, Prise de Parole, 1999, p. 14.

2. Ibid., p. 14-15.

3. Ibid., p. 15. 
d'exemple quelques-unes de ses activités : membre fondateur de la paroisse Sainte-Agnès d'Azilda ; commandeur de l'Ordre de Jacques-Cartier, 19561960 ; président de la Caisse populaire d'Azilda, 1969-1994 ; membre de la chorale paroissiale de Sainte-Agnès d'Azilda depuis 1954 ; président de la Société d'astronomie de Rayside, 1972-1982. Plus tard, il se mériterait la désignation de l'Homme de l'année de la Ville de Rayside-Balfour en reconnaissance de quarante-cinq ans de services bénévoles.

Pourtant, les contes n'étaient pas oubliés. Comme il explique : «[...] je fis la connaissance du père Germain Lemieux, s.j., à l'Université de Sudbury. Le travail qu'il accomplissait en recueillant des contes folkloriques m'intéressait beaucoup. Dans ses livres, je retrouvai plusieurs contes de mon répertoire, mais dans des versions différentes. » Cette découverte provoqua une réaction qui illustre bien le caractère d'Émile : « Ce qui m'en a vraiment donné le goût, c'est lorsque j'ai lu, dans un des livres du père Germain Lemieux, l'histoire de La Bête à sept têtes. J'étais désappointé de voir que c'était pas ça, pas ça, pantoute, La Bête à sept têtes que je connaissais, que j'avais contée dans les chantiers quand j'étais jeune. C'était pas ça que mon père et que mon frère contaient. Je m'étais dit: “Je vas l'écrire une bonne fois cette histoire-là." "4 "

À sa retraite en 1989, Émile a pu retourner à ses contes. L'influence du père Lemieux y joua sans doute un rôle, comme celle de son ami Camille Perron, conteur qui, sous le nom de « Pépère Cam », se produisait dans les écoles à la grandeur du pays dans le but de faire vivre à nouveau cette tradition moribonde. À la mort de monsieur Perron en 1995, le père Lemieux encourage Émile à prendre la relève et il décide de remplir les contrats que son ami avait laissés en suspens : il se retrouva donc comme conteur professionnel. Une rencontre avec l'ethnologue Donald Deschênes, directeur du Centre franco-ontarien de folklore à Sudbury en 1993, donna le dernier coup d'impulsion à la renaissance du conteur. S'intéressant d'abord à son répertoire de chansons, Deschênes réalisa la richesse du répertoire de contes que possédait Émile et l'encouragea à se remémorer et à reconstituer ses contes. Il trouva la tâche ardue, mais irrésistible. Il s'agissait parfois d'histoires qu'il n'avait pas entendues ou racontées depuis plus de quarante ans. Il consultait donc ses frères et ses sœurs, retrouvant un morceau ici et là. Émile décrit le processus : «J'ai quelques éléments et pis je les écris. Il va arriver souvent que j'écris seulement ce dont je me souviens immédiatement. J'ai parfois une espèce de milieu. Je la vois toute dans ma tête, l'histoire. Je me rappelle même des paroles exactes, mais j'ai pas encore l'élément premier. Je sais pas comment les personnages sont arrivés là et comment ils s'en sortent. Tout à

4. Ibid., p. 21. 
coup, l'inspiration m'arrive, souvent le matin. Ça va arriver quelques fois dans une somnolence que je m'adonne à penser à ça ${ }^{5}$ " .

Le résultat de cette heureuse collaboration paraît chez Prise de parole à Sudbury en 1999 sous le titre Les Contes d'Émile et une nuit, collection qui met à l'honneur 35 contes qui représentent bien le répertoire traditionnel : contes d'animaux, contes merveilleux, contes réalistes, contes facétieux et contes à formule. Émile développe un style écrit qui reproduit de près son style oral : simple et direct, imagé, mais très terre à terre, un langage de tous les jours sans recours aux exagérations stylistiques qui passent si souvent comme reproduction de l'oralité. Un disque compact comprenant dix contes et deux chansons, produit en collaboration avec Radio-Canada CBON à Sudbury, accompagne le livre.

Suite à cette publication, la carrière de conteur public d'Émile Maheu monte en flèche et il se retrouve en grande demande à toutes les occasions d'importance dans la francophonie. Conteur en résidence au Centre francoontarien de folklore, il se produit aussi dans les écoles de l'Ontario, du Québec et même du grand Nord canadien. Il est très conscient de sa mission : « Si je les conte pas, ces histoires-là, il y a pas personne d'autre qui va les conter. Elles vont être perdues ${ }^{6} \gg$. Un nouveau recueil, Mon oncle Émile conte, qui paraît chez Prise de parole en 2005, puise dans le même répertoire de contes et légendes, et inclut aussi plusieurs de ses propres créations - histoires créées, toujours, avec le souci de rester fidèle à l'art traditionnel du conteur. Il produit également deux enregistrements sonores - La Fabuleuse Histoire de John Cook, une recréation fidèle d'un des plus longs et plus beaux contes de son père, et Contes pour une fin de siècle, l'enregistrement d'un spectacle qui a eu lieu à la caverne INCO de Science-Nord en décembre 1999. Il tient d'ailleurs, pendant une dizaine d'années, une chronique de contes pour l'hebdomadaire français de Sudbury, Le Voyageur. Il estime avoir rappelé et « mis en écrit » plus de quatre cents récits. Un dernier volume posthume, Contes de Noël, paraîtra à l'automne 2008 aux Éditions du GREF de Toronto.

La communauté francophone a bien su apprécier le travail et le dévouement d'Émile Maheu en lui accordant au fil des ans plusieurs prix et mérites : l'Ordre du mérite des Caisses populaires de l'Ontario, le Mérite Grand-Cœur d'Air Canada, la Distinction de l'Ontario pour bénévolat dans la région et la province, le Mérite Richelieu Horace-Viau et le Billochet du jongleur du Centre franco-ontarien de folklore. Bien que son cœur soit toujours resté dans la Beauce, Émile assuma un rôle important dans la communauté française de sa province d'adoption. À une époque où très peu de gens se souciaient de la tradition orale, Émile Maheu a presque à lui seul reconstitué

5. Ibid., p. 21.

6. Ibid., p. 22. 
l'art du conteur dans cette province. Pigeant dans la mémoire collective de l'Amérique française, il nous a présenté son mélange personnel de tradition orale, de culture populaire et de créativité artistique. Il a fait connaître à de nouvelles générations les histoires de Ti-Jean-Fin-Voleur, Ti-Jean-Joueurde-Tours, de la Bête à sept têtes, du Chasseur chanceux - et combien d'autres - mais, avant tout, il nous a fait rappeler la chaleur et la puissance de la voix humaine qui raconte. Émile Maheu a été un chaînon vivant entre les conteurs traditionnels des foyers et des chantiers et les « néo conteurs » comme Fred Pellerin et Michel Faubert (avec qui il a partagé la scène). Il a inspiré des jeunes conteurs, comme l'étudiant Joseph Gagné de Chapleau, qui prendront un jour la relève. C'est à ce titre que l'œuvre d'Émile Maheu continuera à porter fruit.

Une fois, il y avait un oiseau bleu sur un pieu. L'oiseau est parti, le pieu est resté là.

Marcel BénÉTEAu Université de Sudbury

\section{Publications}

\section{Livres}

Des Hazards [A.-Émile Maheu], Sur les rives du fleuve Saint-Jean, Hanmer, Les Éditions de l'Ami du peuple, [1980], 114 p.

Des Hazards, [A.-Émile Maheu], Dans l'boute du chicot, Hanmer, Les Éditions de l'Ami du peuple, [1983], $109 \mathrm{p}$.

Maheu, Émile et Donald Deschênes, Les Contes d'Émile et une nuit. Contes, Sudbury, Prise de parole [en collaboration avec Cвоn/Radio-Canada] 1999, 310 p. [livre et disque compact].

Maheu, Ange-Émile, Mon oncle Émile conte, Sudbury, Prise de parole [en collaboration avec $\mathrm{CBON}_{\text {B }}$ Radio-Canada], 2005, 282 p. [livre et disque compact].

\section{Disques}

La Fabuleuse Histoire de John Cook, disque compact, Sudbury, CвоN/RadioCanada et Prise de parole, 2002, 45 minutes.

Contes pour une fin de siècle, disque compact, Sudbury, CвоN/Radio-Canada et Prise de parole, 2001, 73 minutes. 